\title{
Ultrasonic Degradation of Endocrine Disrupting Compounds in Seawater and Brackish Water
}

\author{
Soyoung Park ${ }^{1}$, Jong-Sung Park ${ }^{2}$, Hayoon Lee ${ }^{2}$, Jiyong Heo ${ }^{3}$, Yeomin Yoon ${ }^{3}$, Kyungho Choi ${ }^{1}$, \\ Namguk $\mathrm{Her}^{2 \dagger}$ \\ ${ }^{1}$ School of Public Health, Seoul National University, Seoul 151-742, Korea \\ ${ }^{2}$ Department of Chemistry and Environmental Sciences, Korea Army Academy at Young-Cheon, Young-Cheon 770-849, Korea \\ ${ }^{3}$ Department of Engineering, University of South Carolina, Columbia, SC 29208, USA
}

\begin{abstract}
In this study, a series of experiments was conducted on the relative degradation of commonly known endocrine-disrupting compounds such as bisphenol A (BPA) and 17 $\alpha$-ethinyl estradiol (EE2) in a single-component aqueous solution using 28 and $580 \mathrm{kHz}$ ultrasonic reactors. The experiments were conducted with three different types of model water: deionized water (DI), synthetic brackish water (SBW), and synthetic seawater (SSW) at pH 4, 7.5, and 11 in the presence of inert glass beads and humic acids. Significantly higher sonochemical degradation (93-97\% for BPA) occurred at $580 \mathrm{kHz}$ than at $28 \mathrm{kHz}$ (43-61\% for BPA), regardless of water type. A slightly higher degradation was observed for EE2 compared to that of BPA. The degradation rate of BPA and EE2 in DI water, SBW, and SSW after $30 \mathrm{~min}$ of ultrasound irradiation at $580 \mathrm{kHz}$ increased slightly with the increase in pH from $4\left(0.073-0.091 \mathrm{~min}^{-1}\right.$ for BPA and 0.081-0.094 $\mathrm{min}^{-1}$ for EE2) to $7.5\left(0.087-0.114 \mathrm{~min}^{-1}\right.$ for BPA and $0.092-0.124 \mathrm{~min}^{-1}$ for EE2). In contrast, significant degradation was observed at pH $11\left(0.149-0.221 \mathrm{~min}^{-1}\right.$ for BPA and 0.147-0.228 $\mathrm{min}^{-1}$ for EE2). For the given frequencies of 28 and $580 \mathrm{kHz}$, the degradation rate increased in the presence of glass beads $(0.1 \mathrm{~mm}$ and $25 \mathrm{~g})$ for both BPA and EE2: 0.018-0.107 $\mathrm{min}^{-1}$ without beads and $0.052-0.142$ $\mathrm{min}^{-1}$ with beads for BPA; 0.021-0.111 $\mathrm{min}^{-1}$ without beads and $0.054-0.136 \mathrm{~min}^{-1}$ with beads for EE2. A slight increase in degradation of both BPA and EE2 was found as the concentration of dissolved organic carbon (DOC, humic acids) increased in both SBW and SSW: 0.107-0.115 $\mathrm{min}^{-1}$ in SBW and 0.087-0.101 $\mathrm{min}^{-1}$ in SSW for BPA; 0.111-0.111 $\mathrm{min}^{-1}$ in SWB and 0.092-0.105 $\mathrm{min}^{-1}$ in SSW for EE2. After 30 min of sonicating the humic acid solution, DOC removal varied depending on the water type: $27 \%\left(3 \mathrm{mg} \mathrm{L}^{-1}\right)$ and $7 \%\left(10 \mathrm{mg} \mathrm{L}^{-1}\right)$ in SBW and $7 \%\left(3 \mathrm{mg} \mathrm{L}^{-1}\right)$ and $4 \%\left(10 \mathrm{mg} \mathrm{L}^{-1}\right)$ in SSW.
\end{abstract}

Keywords: Bisphenol A, Brackish water, Endocrine disrupting compounds, Seawater, Sonochemical degradation, 17 $\alpha$-ethinyl estradiol

\section{Introduction}

Over 1 billion people do not have access to clean drinking water, and approximately 2.3 billion people $(40 \%$ of the world population) live in regions with water shortages [1]. The exploitation of natural freshwater resources combined with increasing water demand has given rise to a demand for alternative freshwater resources. Both desalination and water reuse have been successfully implemented to provide additional freshwater for communities, using conventional water treatment and freshwater resources $[2,3]$. A great share of the world's desalination capacity is installed in the Middle East, and although reverse osmosis (RO) is rapidly gaining market share, thermal processes still dominate the market in this region due to the low cost of fossil fuel-based energy and the advantage of using such systems to generate electrical energy (cogeneration of steam and electricity) [4].
There are still several limitations for using an RO membrane to treat seawater or brackish water. Inorganics and organics present in water can adhere to the surface and pores of highpressure membranes used for RO and nanofiltration (NF), which results in a deterioration in performance (i.e., membrane flux decline) of the membrane accompanied by a consequent increase in the energy cost and early membrane replacement [5]. One of the major problems encountered in seawater and brackish water treatment using RO and NF membranes is membrane fouling associated with natural organic matter (NOM). NOM is always problematic in the water industry, as it acts as a precursor for the formation of disinfected by-products. Humic substances, which are anionic macromolecules with a wide range of molecular weights, comprise a major fraction of NOM in aquatic environments. Humic substances contain both aromatic and aliphatic components with primarily carboxylic (carboxylic functional groups account for $60-90 \%$ of all functional groups) and (c) This is an Open Access article distributed under the terms of the Creative Commons Attribution Non-Commercial License (http://creativecommons. org/licenses/by-nc/3.0/) which permits unrestricted non-commercial use, distribution, and reproduction in any medium, provided the original work is properly cited.
Received May 23, 2011 Accepted July 14, 2011

${ }^{\dagger}$ Corresponding Author

E-mail: namgukher@daum.net

Tel: +82-54-330-4760 Fax: +82-54-335-5790 
phenolic functional groups [6].

Additionally, emerging micropollutants, including endocrine disrupting compounds (EDCs), have become an issue for wastewater reclamation and seawater treatment. Numerous recent studies have shown that conventional wastewater treatment plants do not completely remove many EDCs and pharmaceuticals and personal care products (PPCPs) [7-9]. These EDCs and PPCPs have been detected at trace concentrations (i.e., $<1 \mu \mathrm{g} / \mathrm{L}$ ) in waters around the world. EDCs, including bisphenol A (BPA), $p$-alkylphenols, and $p$-alkylphenol ethoxylates, have been detected in water samples from the Elbe river (9-776 ng/L for BPA, 10-221 ng/L for $p$-alkylphenols, and 18-302 ng/L for $p$-alkylphenol ethoxylates), whereas concentrations from the North Sea are generally about one order of magnitude lower [10]. This is because the Elbe River is a major pollutant source for the North Sea. Some of the most important and commonly found EDCs include BPA and 17 $\alpha$-ethinyl estradiol (EE2). These compounds are either used in industrial processes (i.e., BPA is used as a plasticizer), or synthetically created for human pharmaceuticals (i.e., EE2 is used as an ovulation inhibitor).

BPA and EE2 are relatively polar compared to currently regulated polyaromatic contaminants. This, coupled with their occurrence at trace levels $\left(<1 \mu \mathrm{g} \mathrm{L}^{-1}\right)$, creates unique challenges for analytical detection and assessment of removal performance by potable water treatment plant processes [11]. The analytical determination of BPA and EE2 from surface and wastewater commonly uses gas chromatography-mass spectrometry (GC-MS or MS/MS) [12, 13], liquid chromatography-mass spectrometry (LC-MS or -MS/MS) [14], and biological assays [15, 16] following solid-phase extraction. In a separate study, a simple analytical technique for rapidly determining BPA and EE2 in drinking water matrices was developed using high-performance liquid chromatography (HPLC) with fluorescence detection [17].

It is necessary to pretreat feed water using RO and NF membranes to lower undesirable fouling materials, including NOM and micropollutants (e.g., EDCs); this is because poor feed water quality leads to a short RO and NF membrane lifetime, short operation period, and high maintenance. Various technologies have been investigated to remove these NOM and EDCs from water and/or wastewater, including biological degradation [18-20], activated carbon adsorption [21-23], and membrane filtration [24-26]. Advanced oxidation processes such as ozone, ozone/ultraviolet (UV), ozone/ultrasound, and UV/hydrogen peroxide $\left(\mathrm{H}_{2} \mathrm{O}_{2}\right)$ play an important role in the removal of NOM and EDCs and are also promising technologies for water and/or wastewater treatment [27-29]. However, chlorination and ozonation increase the estrogenic activity of BPA and EE2 as determined using a human breast cancer cell line (MCF-7) [15]. Sonochemical processes that enhance or promote chemical reactions are an attractive advanced technology for organic contaminant removal from water and wastewater. The process of sonocatalytic degradation has significant advantages because it is easy and safe to operate and produces a minimal amount of toxic byproducts. In general, the sonochemical degradation of pollutants in an aqueous phase occurs as a result of imploding cavitation bubbles and generally involves two reaction pathways, such as pyrolysis inside the bubble and/or at the bubble-liquid interface, and hydroxyl radical-induced reactions at the bubble-liquid interface and/or in the liquid bulk [30]. A previous study has shown effective NOM removal by ultrasonic irradiation [31]. Sonochemical treatment has good potential for degrading organic contaminants, including EDCs and pharmaceuticals [32, 33]. However, these studies were still limited to very low background conductivity in the absence of NOM. Therefore, a degradation assessment for both seawater and brackish water would be useful to investigate the NOM and EDC degradation mechanisms.

The objective of this study was to investigate the degradation of EDCs during sonochemical reactivity with synthetic seawater (SSW) and synthetic brackish water (SBW). To accomplish this, sonodegradation of widely known EDCs (i.e., BPA and EE2) was measured at varying $\mathrm{pHs}$ and NOM levels with different frequencies. The combined effect of frequency and glass beads on EDC degradation was also investigated.

\section{Materials and Methods}

\subsection{Chemicals}

The highly pure ( $>99 \%)$ BPA, EE2, and humic acid used in this study were purchased from Sigma-Aldrich Chemical Co., Inc. (Milwaukee, WI, USA). Solvents (methanol and acetonitrile) were obtained from JT Baker Chemical Co., Inc. (Phillipsburg, PA, USA) and were all of HPLC grade. Table 1 lists the charac-

Table 1. Physicochemical properties of bisphenol A and 17 $\alpha$-ethinyl estradiol [34]

\begin{tabular}{|c|c|c|c|c|c|}
\hline $\begin{array}{c}\text { Compound } \\
\text { (Use) } \\
\text { [Molecular weight] } \\
{[14]}\end{array}$ & $\log K_{\text {ow }}$ & $\begin{array}{c}\mathrm{S}_{\mathrm{W}} \\
\left(\mathrm{mg} \mathrm{L}^{-1}\right)\end{array}$ & $\begin{array}{c}\mathrm{V}_{\mathrm{P}} \\
(\mathrm{mmHg})\end{array}$ &  & Structure \\
\hline $\begin{array}{c}\text { Bisphenol A } \\
\text { (Plasticizer) } \\
{[228.3]} \\
\{10.2\}[64]\end{array}$ & 3.32 & 120 & 3.91E-07 & $1.00 \mathrm{E}-11$ & $\mathrm{CH}_{3}$ \\
\hline $\begin{array}{c}17 \alpha \text {-ethinyl estradiol } \\
\text { (Ovulation inhibitor) } \\
{[296.2]} \\
\{\sim 10.5\}[26]\end{array}$ & 3.67 & 11.3 & $2.67 \mathrm{E}-09$ & $7.94 \mathrm{E}-12$ & \\
\hline
\end{tabular}


teristics of the BPA and EE2, which were obtained from the SRC PhysProp Database [34]. All sample solutions containing each target compound were prepared with ultrapure DI water. BPA and EE2 were dissolved separately in acetonitrile as stock solutions of $1 \mathrm{mM}$ each. A humic acid stock solution was prepared by adding $1 \mathrm{~g}$ of dry humic acid powder to $1 \mathrm{~L}$ of deionized water and stirred overnight. The solution was then filtered through $0.45 \mu \mathrm{m}$ glass microfiber filters (Whatman, Buckinghamshire, UK) to remove particulate matter $>0.45 \mu \mathrm{m} . \mathrm{Na}_{2} \mathrm{SO}_{4}$, $\mathrm{KCl}, \mathrm{NaHCO}_{3}, \mathrm{MgCl}_{2}$, and $\mathrm{CaCl}_{2}$ were purchased from SigmaAldrich. NaCl was purchased from Fisher-Scientific (Pittsburgh, PA, USA). Glass beads of $0.1 \mathrm{~mm}$ diameter were purchased from Goryeo-Ace Inc. (Seoul, Korea).

\subsection{Preparation of SSW and SBW}

Solutions of SSW and SBS were prepared to investigate the sonodegradation of BPA and EE2 from seawater and brackish water. Volumes of BPA and EE2 stock solutions were both placed together in separate beakers at concentrations of $1 \mu \mathrm{M}$, and the acetonitrile was evaporated from the stock solution at room temperature under a fume hood to remove dissolved organic carbon (DOC). Dilutions of humic acid were taken from the stock solution and added to achieve the desired concentration of DOC. Based on a preliminary DOC analysis, the humic acid used in this study consisted of $10 \%$ DOC. Then, the other constituents in the synthetic source water were added using the concentrations listed in Table 2 and stirred overnight. The compositions of the SSW and SBS were based on a literature review of several studies related to the treatment and characterization of seawater and brackish water $[35,36]$. The $\mathrm{pH}$ was adjusted to the desired values using $1 \mathrm{M} \mathrm{NaOH}$ and/or $\mathrm{HCl}$.

\subsection{Experimental Setup}

A schematic diagram of the experimental setup is shown in Fig. 1. Ultrasonic irradiation of the aqueous samples was performed in a stainless steel bath-type reactor $(15 \mathrm{~cm}$ length $\times 10$ $\mathrm{cm}$ width $\times 20 \mathrm{~cm}$ height; Ul-Tech, Seoul, Korea) at two different

Table 2. Characteristics of the synthetic seawater and brackish water used in the study

\begin{tabular}{ccc}
\hline \multirow{2}{*}{$\begin{array}{c}\text { Chemical ion } \\
(\mathbf{m g} / \mathrm{L})\end{array}$} & \multicolumn{2}{c}{ Synthetic source water } \\
\cline { 2 - 3 } $\mathrm{Cl}^{-}$ & Seawater & Brackish water \\
$\mathrm{Na}^{+}$ & 19,350 & 1,300 \\
$\mathrm{SO}_{4}{ }^{2-}$ & 10,770 & 830 \\
$\mathrm{Mg}^{2+}$ & 2,710 & 550 \\
$\mathrm{Ca}^{2+}$ & 1,290 & 100 \\
$\mathrm{~K}^{+}$ & 410 & 100 \\
$\mathrm{HCO}^{3-}$ & 360 & 50 \\
$\mathrm{DOC}$ & 140 & 140 \\
$\mathrm{TDS}$ & \multicolumn{2}{c}{$<, 080$} \\
$\mathrm{pH}$ & 35,030 & \multicolumn{2}{c}{$4,7.5$, and 11} \\
\hline
\end{tabular}

DOC: dissolved organic carbon, TDS: total dissolved solid.

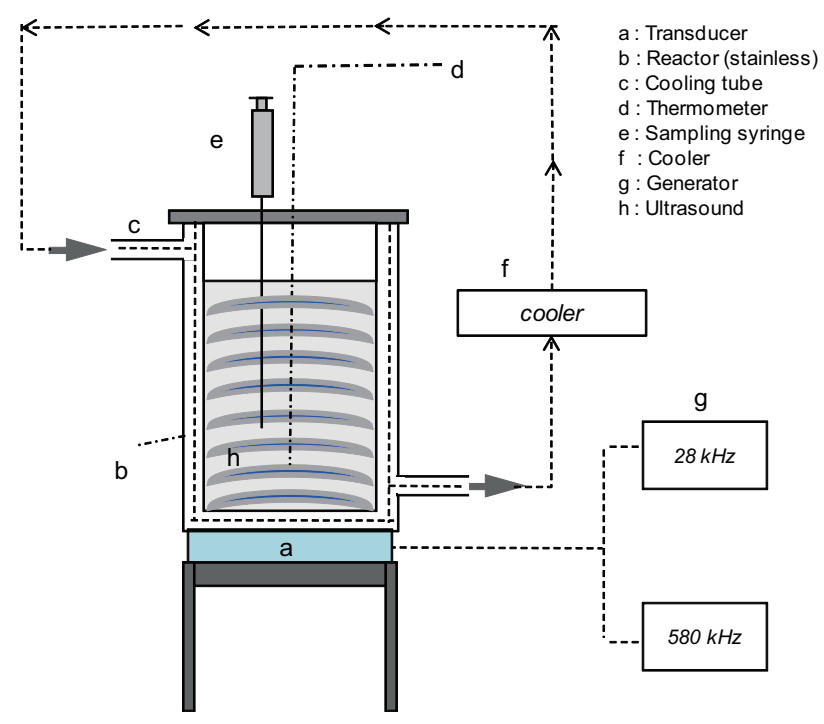

Fig. 1. Schematic of the ultrasound system.

frequencies of 28 and $580 \mathrm{kHz}$ with an applied power of $200 \pm 3$ $\mathrm{W}$ and at a constant temperature of $20 \pm 1^{\circ} \mathrm{C}$. Volumes of 1,000 $\mathrm{mL}$ each for DI water, SSW, and SBW were poured into the reactor bath, which was connected to a temperature control unit (Thermo Haake, Karlsruhe, Germany). All glassware (sample bottles, beakers, test tubes, and LC inserts) for the experiments were silanized prior to use [37]. Furthermore, all glassware and supplies were rinsed twice with methanol. The power density applied to the solution was $0.2 \mathrm{~W} \mathrm{~mL}^{-1}$. Aliquots of $1.5 \mathrm{~mL}$ each were withdrawn at set intervals of 5 min over the total irradiation time of $30 \mathrm{~min}$. Blank control tests were also performed in a single component in the absence of ultrasonic irradiation for 30 $\mathrm{min}$ at a room temperature of approximately $20^{\circ} \mathrm{C}$. No change in the BPA and EE2 concentrations were observed. Some of the values reported are an average of experimental results performed in triplicate.

\subsection{Analysis Using HPLC-fluorescence}

HPLC-fluorescence was conducted on Agilent Technologies 6410 and 1200 Series instruments (Santa Clara, CA, USA) to perform a sensitive and simple analysis of the target compounds. The HPLC-fluorescence system was equipped with a C18 reverse column $(150 \times 4.6 \mathrm{~mm}, 5 \mu \mathrm{m})$ (Agilent Technologies) for determining BPA and EE2 levels. Fluorescence detection was performed using a fluorescence detector at an excitation wavelength of $280 \mathrm{~nm}$ and an emission wavelength of $310 \mathrm{~nm}$ to identify BPA and EE2. The mobile-phase solvent profile was $30 \%$ DI water and $70 \%$ methanol for $10 \mathrm{~min}$ at a constant flow rate of $1 \mathrm{~mL} \mathrm{~min}^{-1}$ with a sample injection volume of $10 \mu \mathrm{L}$. The concentration of each in the samples was determined against an external calibration curve with five different concentrations of $0.01,0.05,0.1,0.5$, and $1 \mu \mathrm{M}$ prepared in DI water. Calibration standards of $0.05 \mu \mathrm{M}$ were run between approximately every 10 samples. The method detection limits were $0.13 \mathrm{nM}$ for BPA and $1.29 \mathrm{nM}$ for EE2.

An aqueous KI solution was used to determine the concentration of hydrogen peroxide formed during aqueous sonolysis 

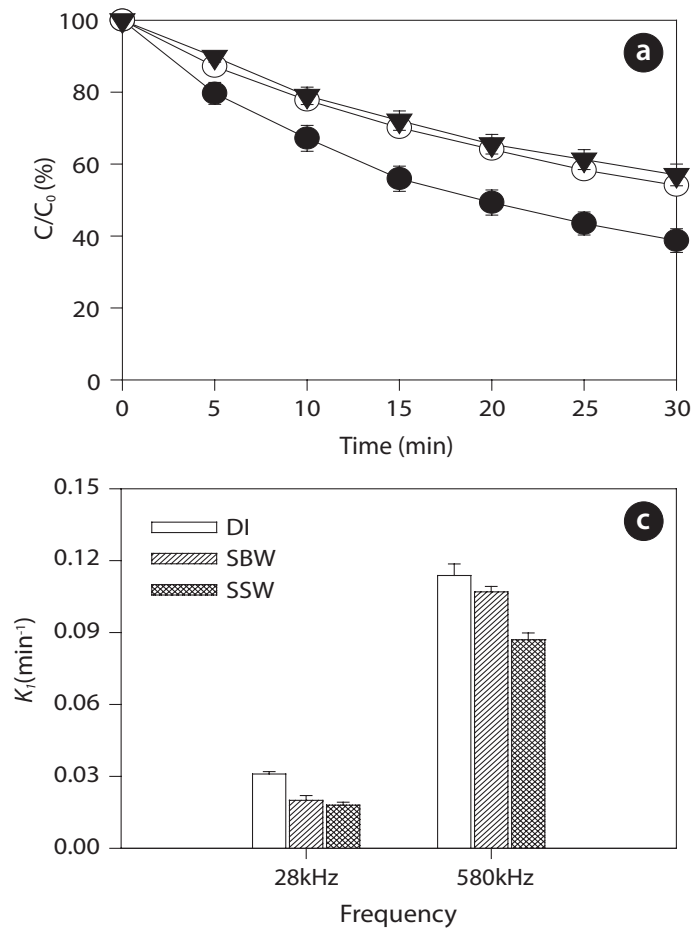

[38]. A sample of $1.5 \mathrm{~mL}$ was collected, and $0.75 \mathrm{~mL}$ of $0.1 \mathrm{M}$ potassium hydrogen phthalate was added. An iodide reagent $(0.75$ $\mathrm{mL})\left(0.4 \mathrm{M}\right.$ potassium iodide, $0.06 \mathrm{M} \mathrm{NaOH}$, and $10^{-4} \mathrm{M}$ ammonium molybdate) was added at $t=0 \mathrm{~min}$. The solution mixtures were allowed to stand for $2 \mathrm{~min}$, and the absorbance at $350 \mathrm{~nm}$ was then measured using a UV spectrophotometer (Hewlett Packard, Boeblingen Germany). DOC was measured using UVvisible spectroscopy (Agilent Technologies). Preliminary experiments showed that the correlation of DOC and absorbance at $254 \mathrm{~nm}$ was close to linear in both DI water and seawater. UV absorbance (UVA) is a good alternative for DOC analysis of seawater samples and provides high precision at low DOC levels. A similar method was used in a previous study [35].

\section{Results and Discussion}

\subsection{BPA and EE2 Degradation at Different Frequencies}

Ultrasonic degradation of the two EDC compounds (i.e., BPA and EE2) in aqueous solution with an initial concentration of 1 $\mu \mathrm{M}$ was performed in single-component batch reactors at two frequencies of 28 and $580 \mathrm{kHz}$ with DI water, SBW, and SSW. The ultrasound-assisted degradation and pseudo-first order rate constants of the BPA and EE2 in each case are shown in Figs. 2 and 3. Significantly higher sonochemical degradation (93-97\% for BPA) occurred at $580 \mathrm{kHz}$ than at $28 \mathrm{kHz}$ (43-61\% for BPA), regardless of water type (Fig. 2). Slightly higher degradation of EE2 $(94-98 \%$ at $580 \mathrm{kHz}$ and $48-67 \%$ at $28 \mathrm{kHz})$ was observed compared to that of BPA (Fig. 3). To bring water into cavitation requires more energy at a higher frequency $(487 \mathrm{kHz})$ than at 20 $\mathrm{kHz}$, and the threshold of cavitation is lower for water saturated with air than for degassed water [39]. In our study, cavitation oc-

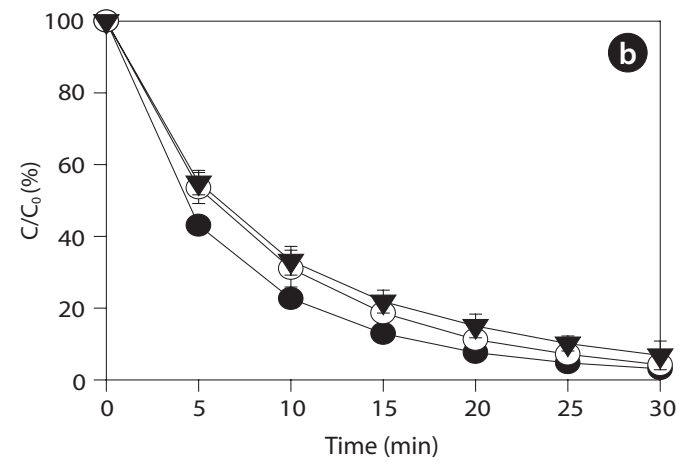

Fig. 2. Comparison of bisphenol A (BPA) sonodegradation in various water types at (a) $28 \mathrm{kHz}$ and (b) $580 \mathrm{kHz}$. (c) Comparison of pseudo-first order rate constants at different frequencies. Sonication conditions: $0.2 \mathrm{~W} \mathrm{~mL}$ ${ }^{1}$; $20 \pm 1^{\circ} \mathrm{C}$; $\mathrm{pH} 7.5$; no humic acid added; $\mathrm{C}_{o}=1 \mu \mathrm{M}(\bullet$ : deionized water $[\mathrm{DI}], \circ$ : synthetic brackish water $[\mathrm{SBW}]$, $\boldsymbol{\nabla}$ : synthetic seawater [SSW]). curred mainly at the surface of the emitter at $28 \mathrm{kHz}$, where the amplitude of the pressure was maximum, whereas at the higher frequency of $580 \mathrm{kHz}$, the degassing effect can be important at the surface of the emitter, which increases the threshold of cavitation [40]. In addition, this occurs most likely because a higher frequency actually increases the number of free radicals in the system. The mechanism for sonochemical degradation of organic compounds involves the production of free radicals and their subsequent attack on pollutant species [41, 42].

Among the three types of water, the degradation of BPA and EE2 followed this order: DI water $>$ SBW $>$ SSW at a contact time of $30 \mathrm{~min}$. These results are contradictory to those of a previous study, in which a significant increase in degradation rate constants of various estrogens was observed in the presence of $\mathrm{NaCl}$ $(0-0.17 \mathrm{M})$ [27]. The enhanced degradation rate due to salinity can be explained by two mechanisms: 1) the "salting out" effect due to $\mathrm{NaCl}$, resulting in higher mass transfer of estrogen hormones from the bulk solution to the interfacial region; and 2) solution salinity can also decrease the vapor pressure and increase the surface tension of the aqueous medium, which promotes a more violent cavity implosion. Both the "salting out" effect and enhanced cavity implosion create favorable conditions for the sonochemical degradation of estrogen compounds [27]. However, in our study, sonodegradation was reduced in the presence of various mono- and divalent anions and cations. Thus, it is necessary to further investigate the effect of ions on sonodegradation, because a previous study has shown that a decrease in the rate of $n$-nitrophenol (NP) degradation occurs by increasing the concentration of phosphate and bicarbonate ions [43]. For low solubility and relatively high $\log \mathrm{K}_{\mathrm{OW}}$ BPA and EE2, they were assumed to have a high tendency to diffuse into the cavity-liquid inference region. Additionally, oxidative degradation by $\mathrm{HO} \bullet$ inside or near the interface can also occur. However, $\mathrm{HCO}_{3}^{-}$is a 



well-known $\mathrm{HO} \bullet$ scavenger [44]. Therefore, $\mathrm{HCO}_{3}{ }^{-}$competes for available $\mathrm{HO} \bullet$ in the SBW and SSW solutions and decreases the BPA and EE2 reaction with $\mathrm{HO} \cdot$.

It is well accepted that $\mathrm{H}_{2} \mathrm{O}_{2}$ arises from the reactions of $\mathrm{HO} \cdot$ and $\mathrm{HOO} \cdot$ in the liquid phase around the cavitational bubble and can be used to quantify the efficacy of reactors for generating the desired cavitational intensity [45]. These radicals are capable of initiating or promoting numerous fast reduction-oxidation reactions. In our study, $\mathrm{H}_{2} \mathrm{O}_{2}$ measurements were performed in the absence of the target compounds to investigate the efficacy of different sonochemical reactors for generating free radical species. The concentration of generated $\mathrm{H}_{2} \mathrm{O}_{2}$ increased linearly with the time of ultrasonic irradiation (Table 3). The $\mathrm{H}_{2} \mathrm{O}_{2}$ concentration values obtained at $28 \mathrm{kHz}$ at a reaction time of $30 \mathrm{~min}$ were much lower than those obtained at $580 \mathrm{kHz}$. In addition, the $\mathrm{H}_{2} \mathrm{O}_{2}$ concentration was slightly higher in DI water than that in SBW and SSW. A statistical analysis of the data revealed that BPA and EE2 degradation followed pseudo-first order kinetics. The degradation rate constants are presented in Figs. 2c and 3c

Table 3. Hydrogen peroxide production in deionized (DI) water

\begin{tabular}{ccc}
\hline Time (min) & $\mathbf{2 8 ~} \mathbf{~ H z}\left(\mathbf{m g ~ L}^{-1}\right)$ & $\mathbf{5 8 0 ~} \mathbf{~ H z}\left(\mathbf{m g ~ L}^{-1}\right)$ \\
\hline 5 & 0.0045 & 0.653 \\
10 & 0.0158 & 1.334 \\
15 & 0.0284 & 2.047 \\
20 & 0.0632 & 2.872 \\
25 & 0.0895 & 3.589 \\
30 & 0.1115 & 4.434 \\
\hline
\end{tabular}



Fig. 3. Comparison of $17 \alpha$-ethinyl estradiol (EE2) sonodegradation in various water types at (a) $28 \mathrm{kHz}$ and (b) $580 \mathrm{kHz}$. (c) Comparison of pseudo-first order rate constants at different frequencies. Sonication conditions: $0.2 \mathrm{~W} \mathrm{~mL}^{-1} ; 20 \pm 1^{\circ} \mathrm{C}$; $\mathrm{pH} 7.5$; no humic acid added; $\mathrm{C}_{0}=1 \mu \mathrm{M}(\bullet$ : deionized water [DI], ○: synthetic brackish water [SBW], $\mathbf{\nabla}$ : synthetic seawater [SSW]).

for the different frequencies. EE2 degraded slightly faster than BPA with rate constants of 0.092-0.114 $\mathrm{min}^{-1}$ for EE2 and 0.087$0.113 \mathrm{~min}^{-1}$ for BPA at $580 \mathrm{kHz}$ in the three different water types. A previous study has shown that the best degradation rate of BPA at four frequencies $(300,500,600$, and $800 \mathrm{kHz})$ was obtained at the lowest frequency [46]. A high BPA degradation ( $>99 \%$ ) at an initial concentration of $118 \mu \mathrm{mol} \mathrm{L}^{-1}$ and contact time of $120 \mathrm{~min}$ was obtained using a $300 \mathrm{kHz}$ frequency [47]. Both BPA and EE2 have a phenol group in the benzene ring, which is presumably where radical attacks and degradation occur. The EDC degradation reaction can be initiated by adding $\mathrm{HO} \cdot$ radicals followed by the ring cleavage/opening mechanism [48].

\subsection{Effect of $\mathrm{pH}$}

Several studies have shown that $\mathrm{pH}$, which can modify the physical properties (e.g., charge) of molecules with ionizable functional groups, plays an important role in the sonochemical degradation of contaminants $[49,50]$. As the charge of the BPA and EE2 compounds is $\mathrm{pH}$-dependent, several experiments were conducted to determine the influence of $\mathrm{pH}$ on the degradation of the compounds in the range of initial pHs of 4 to 11 . Figs. 4 and 5 show that the BPA and EE2 degradation rates in DI water, SBW, and SSW after 30 min of ultrasound irradiation at $580 \mathrm{kHz}$ increased slightly along with an increase in $\mathrm{pH}$ from 4 (0.073-0.091 $\mathrm{min}^{-1}$ for BPA and $0.081-0.094 \mathrm{~min}^{-1}$ for EE2) to $7.5\left(0.087-0.114 \mathrm{~min}^{-1}\right.$ for BPA and $0.092-0.124 \mathrm{~min}^{-1}$ for EE2), whereas a significant increase in degradation was observed at pH 11 (0.149-0.221 $\mathrm{min}^{-1}$ for BPA and 0.147-0.228 $\mathrm{min}^{-1}$ for EE2). These results suggest that BPA and EE2 are unstable in a high $\mathrm{pH}$ solution (i.e., $\mathrm{pH}>\mathrm{pKa}$, where BPA and EE2 are dissociated), and that irradiation with ultrasound significantly accelerates degradation even in water with high ionic strength and salinity such 

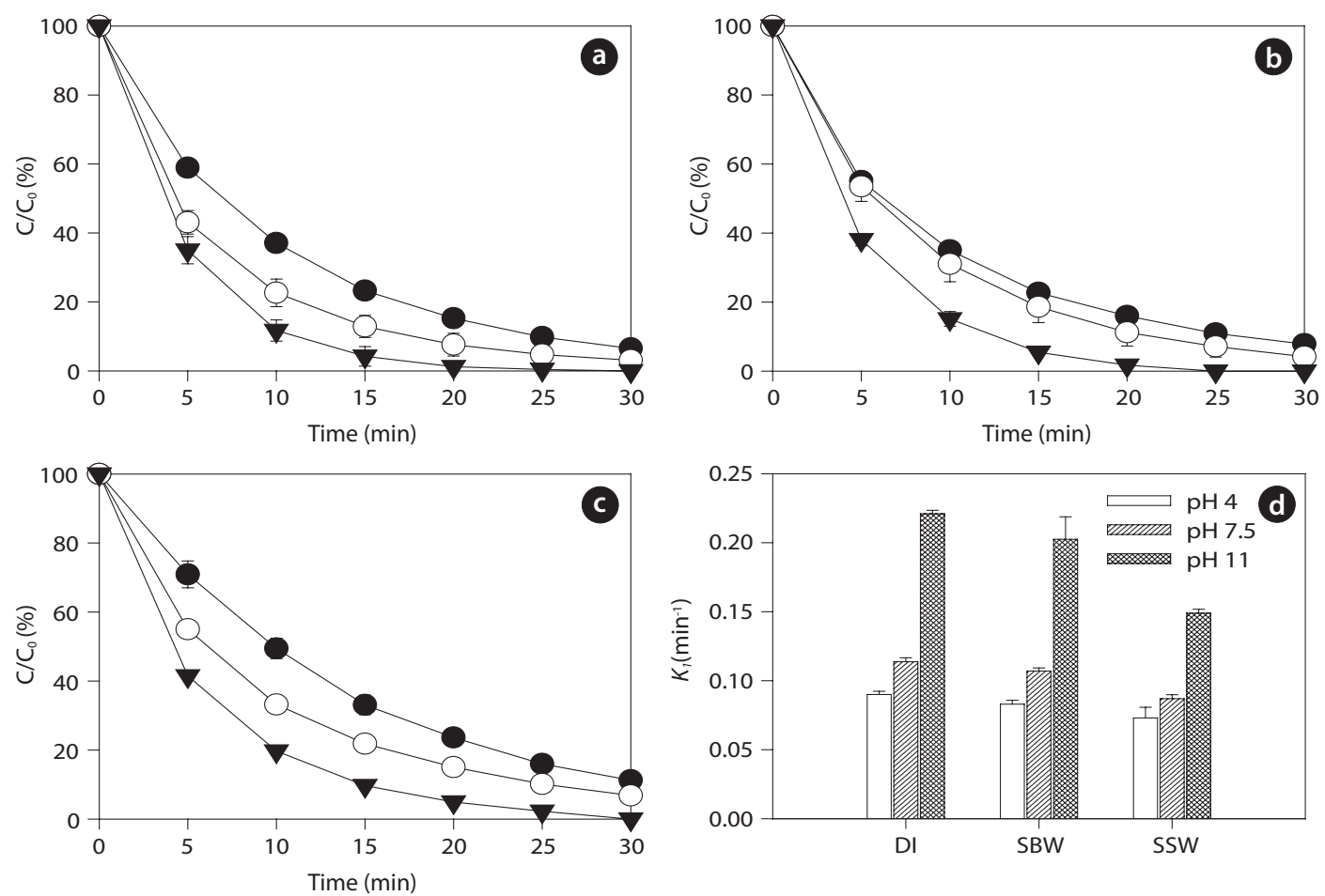

Fig. 4. Comparison of bisphenol A (BPA) sonodegradation in (a) deionized water (DI), (b) synthetic brackish water (SBW), and (c) synthetic seawater (SSW). (d) Comparison of pseudo-first order rate constants at different $\mathrm{pH}$ levels. Sonication conditions: $0.2 \mathrm{~W} \mathrm{~mL}{ }^{-1} ; 20 \pm 1^{\circ} \mathrm{C} ; 580$ kHz; no humic acid added; $\mathrm{C}_{0}=1 \mu \mathrm{M}(\bullet: \mathrm{pH} 4, \circ: \mathrm{pH} 7.5, \boldsymbol{\nabla}: \mathrm{pH} 11)$.
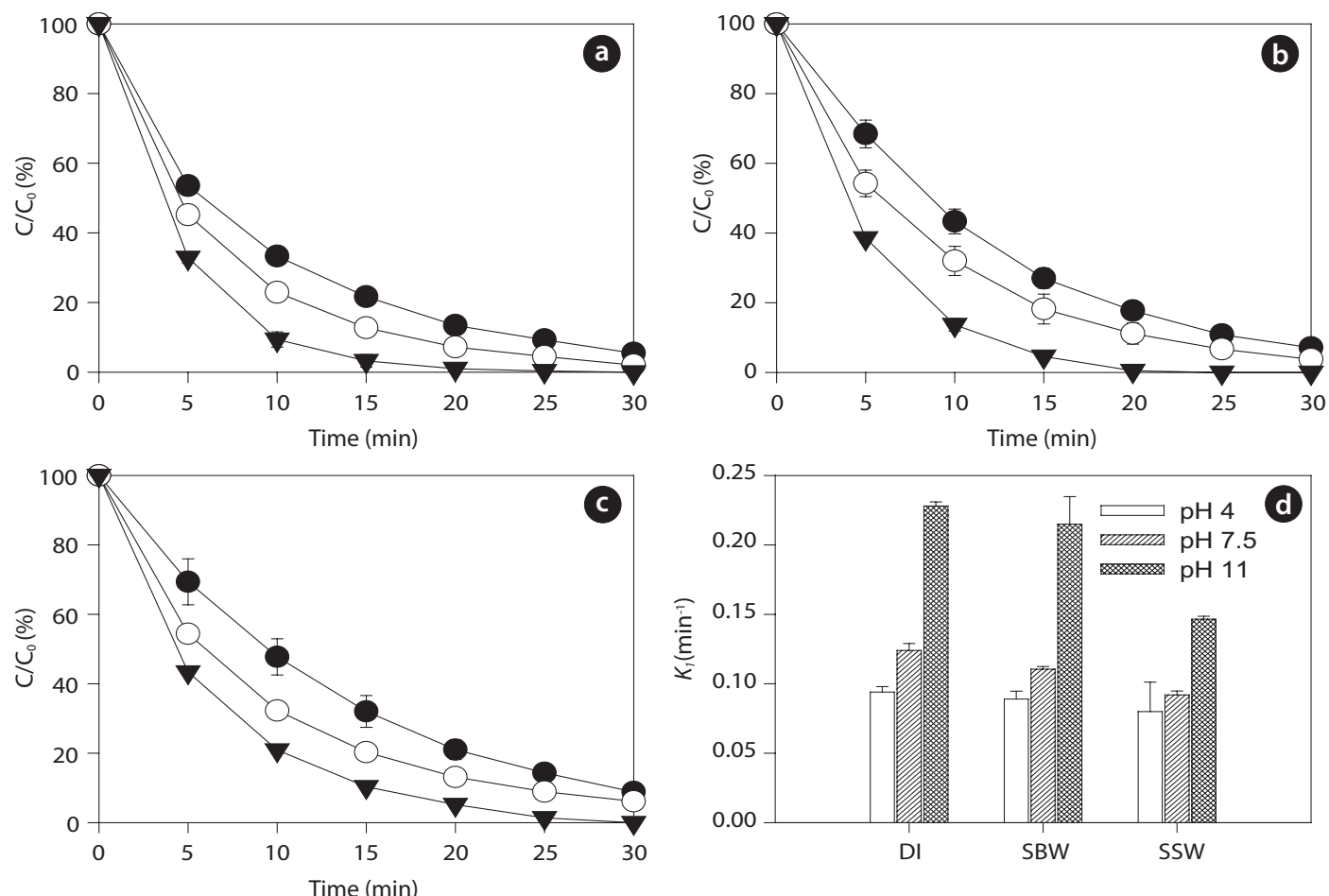

Fig. 5. Comparison of $17 \alpha$-ethinyl estradiol (EE2) sonodegradation in (a) deionized water (DI), (b) synthetic brackish water (SBW), and (c) synthetic seawater (SSW). (d) Comparison of pseudo-first order rate constants at different $\mathrm{pH}$ levels. Sonication conditions: $0.2 \mathrm{~W} \mathrm{~mL}^{-1} ; 20 \pm 1^{\circ} \mathrm{C}$; $580 \mathrm{kHz}$; no humic acid added; $\mathrm{C}_{\mathrm{o}}=1 \mu \mathrm{M}(\bullet: \mathrm{pH} 4, \circ: \mathrm{pH} 7.5, \mathbf{\nabla}: \mathrm{pH} 11)$. 

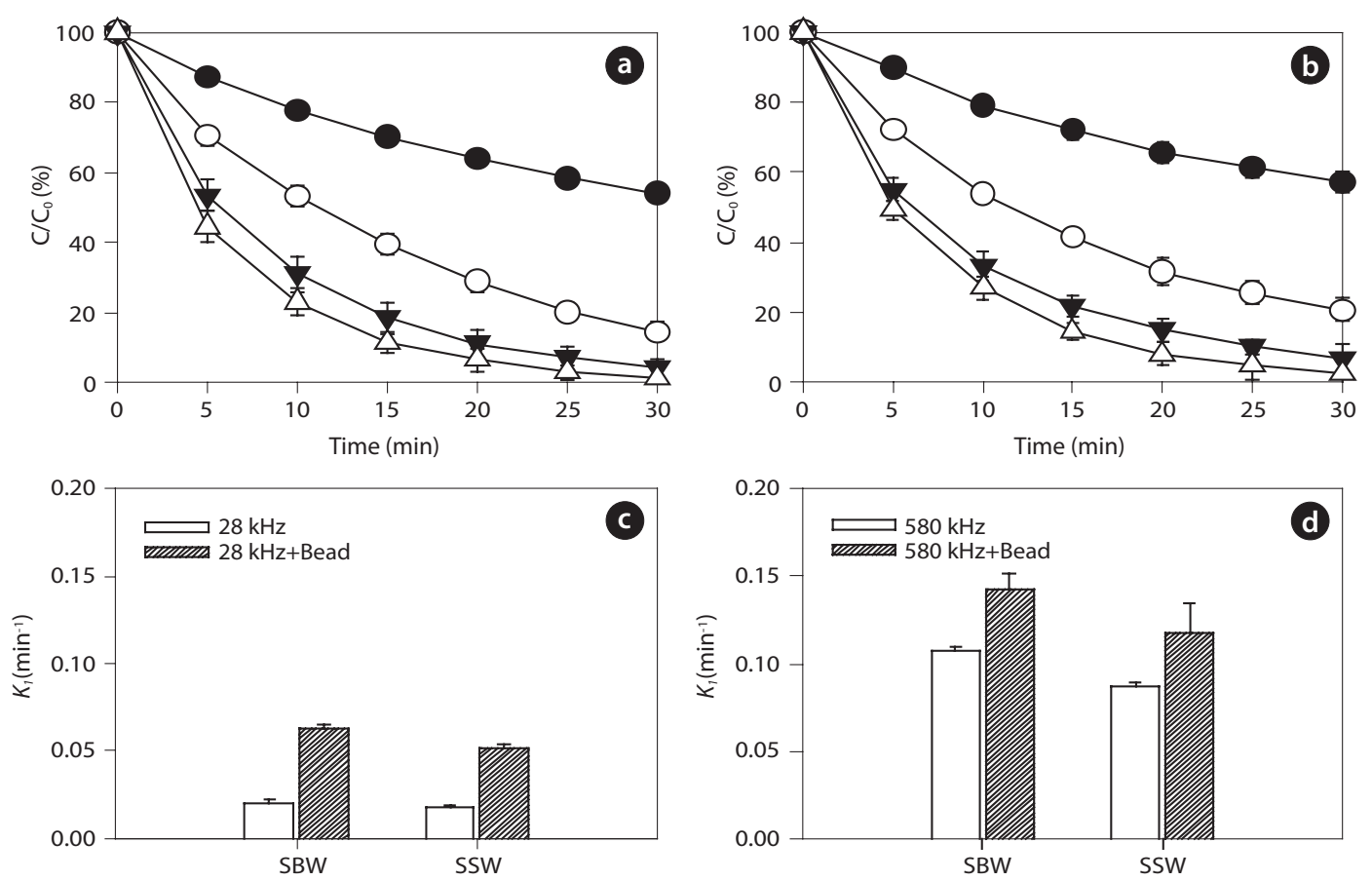

Fig. 6. Comparison of bisphenol A (BPA) sonodegradation in (a) synthetic brackish water (SBW) and (b) synthetic seawater (SSW) in the absence and presence of inert glass beads. Comparison of pseudo-first order rate constants at (c) $28 \mathrm{kHz}$ and (d) $580 \mathrm{kHz}$. Sonication conditions: $0.2 \mathrm{~W} \mathrm{~mL}^{-1} ; 20 \pm 1^{\circ} \mathrm{C} ; 25 \mathrm{~g}$ bead (size: $\left.0.1 \mathrm{~mm}\right)$; pH 7.5; no humic acid added; $\mathrm{C}_{\mathrm{o}}=1 \mu \mathrm{M}(\bullet: 28 \mathrm{kHz}, \circ: 28 \mathrm{kHz}+$ bead, $\mathbf{\nabla}: 580 \mathrm{kHz}, \Delta$ : $580 \mathrm{kHz}+$ bead).

as SBW and SSW. BPA and EE2 seemed to easily attach to HO• in alkaline solutions $(\mathrm{pH}>7)$. A separate study has shown that at $\mathrm{pH}$ values higher than the $\mathrm{pKa}$ of $p$-nitrophenol, the molecule becomes negatively charged and is repulsed by bubble surfaces; thus, being displaced away from the interface region where the main decomposition reactions are expected to occur [43]. As described previously, the presence of $\mathrm{H}_{2} \mathrm{O}_{2}$ further enhances the BPA and EE2 degradation, and the degradation decreases with decreasing $\mathrm{H}_{2} \mathrm{O}_{2}$ concentration. Among the three types of water, the degradation of BPA and EE2 also followed the order: DI water $>$ SBW $>$ SSW at a contact time of $30 \mathrm{~min}$ due to the reasons described previously.

\subsection{Effect of Inert Glass Beads}

Inert glass beads with a size of $0.1 \mathrm{~mm}(25 \mathrm{~g})$ were added to aqueous samples at $\mathrm{pH} 7.5$ to investigate the effect of solid surfaces on ultrasonic reactivity. For the given frequencies of 28 and $580 \mathrm{kHz}$, degradation rate increased in the presence of glass beads for both BPA and EE2, as shown in Figs. 6 and 7, respectively: 0.018-0.107 $\mathrm{min}^{-1}$ without beads and 0.052-0.142 $\mathrm{min}^{-1}$ with beads for BPA; 0.021-0.111 $\mathrm{min}^{-1}$ without beads and $0.054-$ $0.136 \mathrm{~min}^{-1}$ with beads for EE2. In general, higher degradation of both BPA and EE2 was observed at $580 \mathrm{kHz}$ compared to that at $28 \mathrm{kHz}$. Additionally, SBW showed higher BPA and EE2 degradation than SSW. In the presence of glass beads, possible mechanisms of enhanced $\mathrm{H}_{2} \mathrm{O}_{2}$ reactivity include 1) catalytic effects at the solid surface, 2) increased/decreased lifetime of $\mathrm{H}_{2} \mathrm{O}_{2}$ in the solid surface microenvironment, and 3) changes in the salvation shell morphology of sorbed $\mathrm{H}_{2} \mathrm{O}_{2}$ [51]. Furthermore, $\mathrm{H}_{2} \mathrm{O}_{2}$ formation is enhanced by increasing the bubble population in a stand- ing wave field due to shorter intervals between the active regions corresponding to a decrease in the wavelength [52].

Previous studies have reported that the presence of solids and/or catalysts in aqueous systems increases sonochemistry reactivity [51, 53, 54]. A description of the formation and subsequent dynamic life of cavitation bubbles near a solid boundary in an acoustic field remains difficult. Fig. 8 shows the potential cavitation processes in the presence of glass beads at different frequencies in the four bubble collapses: 1) toroidal, 2) spherical, 3) symmetric, and 4) asymmetric (microjet effect). The growth and collapse of cavitation bubbles in an acoustic system is influenced by ultrasound frequency, and the life cycles are very short. Except for frequencies in excess of a few megahertz, a cavitation bubble theoretically grows during the negative portion of the acoustic cycle and is forced to collapse during the positive portion [55]. For similar acoustic intensities and pressure amplitudes, cavitation bubbles at low frequencies $(\sim 20 \mathrm{kHz})$ grow for approximately $25 \mu \mathrm{s}$, whereas cavitation bubbles at high acoustic frequencies $(\sim 1 \mathrm{MHz})$ have only $0.5 \mu$ s of growth [56]. These significant differences in bubble growth result in small bubble sizes at high frequencies and, consequently, less violent collapses: approximately $10-50 \mu \mathrm{m}$ at low frequencies such as $28 \mathrm{kHz}$ and $2.5-3.0 \mu \mathrm{m}$ at medium-high frequencies such as $580 \mathrm{kHz}$, as shown in Fig. 8 [57-59].

For solid surfaces, a previous study reported that a cavitation bubble collapse process is achieved in two acoustic cycles [60]: 1) a spherical bubble collapsed towards the solid boundary to its minimum volume and then rebounded and grew into a toroidal bubble (or two individual bubbles) in one acoustic cycle; and 2) a toroidal bubble (or two individual bubbles) collapsed towards the center of the ring to its minimum volume and then rebound- 



Fig. 7. Comparison of $17 \alpha$-ethinyl estradiol (EE2) sonodegradation in (a) synthetic brackish water (SBW) and (b) synthetic seawater (SSW) in the absence and presence of inert glass beads. Comparison of pseudo-first order rate constants at (c) $28 \mathrm{kHz}$ and (d) $580 \mathrm{kHz}$. Sonication conditions: $0.2 \mathrm{~W} \mathrm{~mL}^{-1} ; 20 \pm 1^{\circ} \mathrm{C} ; 25 \mathrm{~g}$ bead (size: $\left.0.1 \mathrm{~mm}\right) ; \mathrm{pH} 7.5$; no humic acid added; $\mathrm{C}_{0}=1 \mu \mathrm{M}(\bullet: 28 \mathrm{kHz}, \circ: 28 \mathrm{kHz}+\mathrm{bead}, \boldsymbol{\nabla}: 580 \mathrm{kHz}, \Delta$ : $580 \mathrm{kHz}+$ bead).

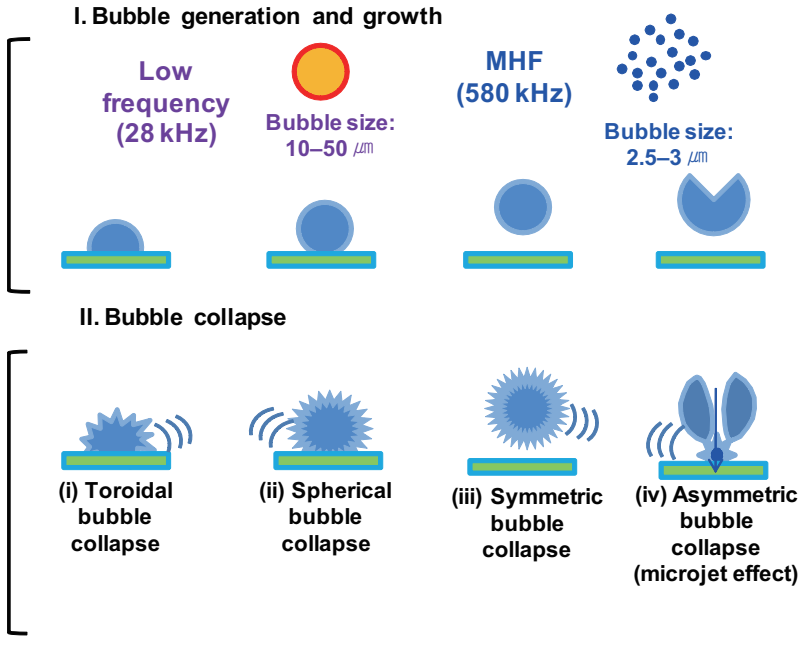

Fig. 8. Pattern of cavitation process: four different collapse effects.

ed into a spherical bubble during the next acoustic cycle (Fig. 8). Asymmetric bubble collapses with a vortex ring produce sonoluminescence in heterogeneous sonochemistry; this results in free radical production in the near vicinity of the solid surface, a rich region for sonochemical reactions [56]. The population (i.e., number and size) of cavitation bubbles depends on the frequency of irradiation. It is well known that lower irradiation frequencies produce a smaller number of cavitation bubbles, as bubbles then grow to a greater extent and undergo higher compression [61]. At a low frequency, bubbles have relatively more time to grow and collapse, which results in large maximum sizes and more violent collapses. In our study, at the low frequency of $28 \mathrm{kHz}$, an assumption was made that the time available and the amount of water vapor during the growth phase of the cavitation bubbles can be expected to be higher in the presence of glass beads compared to without adding glass beads. Thus, an increase in $\mathrm{H}_{2} \mathrm{O}_{2}$ production can be expected as glass beads are added.

\subsection{Effect of NOM}

Figs. 9 and 10 show the effects of increased concentrations of DOC on the sonodegradation of BPA and EE2, respectively, at $580 \mathrm{kHz}$. A slight increase in degradation of both BPA and EE2 was found as the concentration of DOC increased in both SBW and SSW: $0.107-0.115 \mathrm{~min}^{-1}$ in SBW and $0.087-0.101 \mathrm{~min}^{-1}$ in SSW for BPA; 0.111-0.111 $\mathrm{min}^{-1}$ in SWB and 0.092-0.105 $\mathrm{min}^{-1}$ in SSW for EE2. Between these water types, SBW resulted in slightly higher degradation than that of SSW. These results contradict those for the NOM effect on sonodegradation. In a previous study, adding fulvic acid resulted in a decrease in polycyclic aromatic hydrocarbons (anthracene, phenanthrene, and pyrene) [62]. As described previously, reactive transients such as HO• are formed during sonication. These transients then act as oxidants to degrade the pollutants present. However, scavenging of reactive transients results in a continuously decreasing rate constant with added scavenger (fulvic acid) [62]. However, in our study, the degradation of BPA and EE2 increased slightly in the pres- 

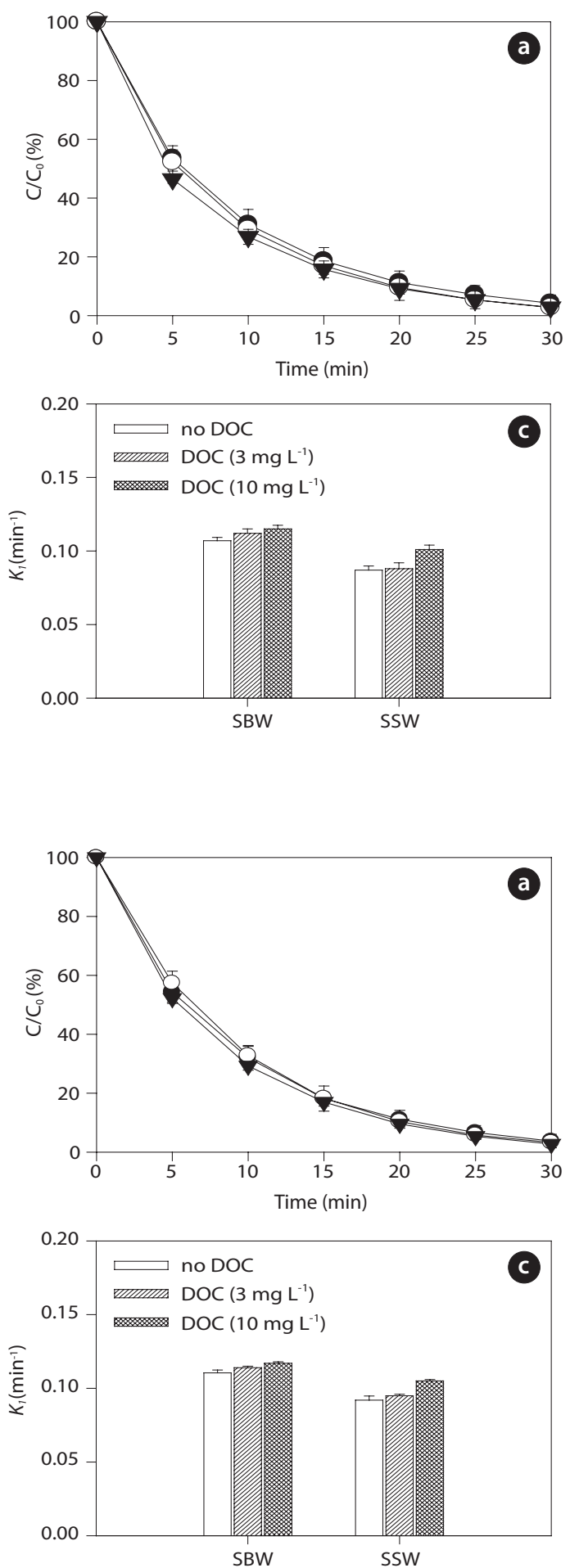

ence of humic acids. Unlike fulvic acid, it seems that humic acids do not react well with $\mathrm{HO}$. It is still unclear how this occurs in SBW and SSW. However, an assumption can be made that humic acids associated with high salts in SBW and SSW react as an $\mathrm{H} \bullet$ scavenger.

It is generally known that a major reduction in $\mathrm{HO} \cdot$ during

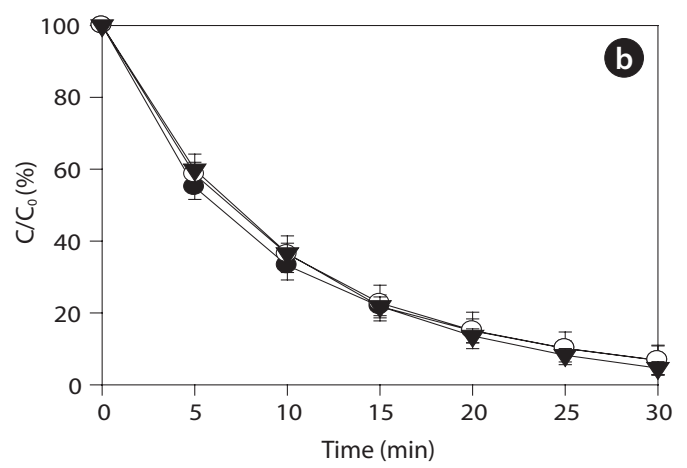

Fig. 9. Comparison of bisphenol A (BPA) sonodegradation in (a) synthetic brackish water (SBW) and (b) synthetic seawater (SSW) in the presence of dissolved organic carbon (DOC). (c) Comparison of pseudo-first order rate constants at different DOC concentrations. Sonication conditions: $0.2 \mathrm{~W} \mathrm{~mL}^{-1} ; 20 \pm 1^{\circ} \mathrm{C} ; 580 \mathrm{kHz} ; \mathrm{pH} 7.5 ; \mathrm{C}_{0}=1$ $\mu \mathrm{M}\left(\bullet\right.$ : no DOC (humic acid) added, $\circ: 3 \mathrm{mg} \mathrm{L}^{-1}$ DOC, $\mathbf{\nabla}$ : $\left.10 \mathrm{mg} \mathrm{L}^{-1} \mathrm{DOC}\right)$.

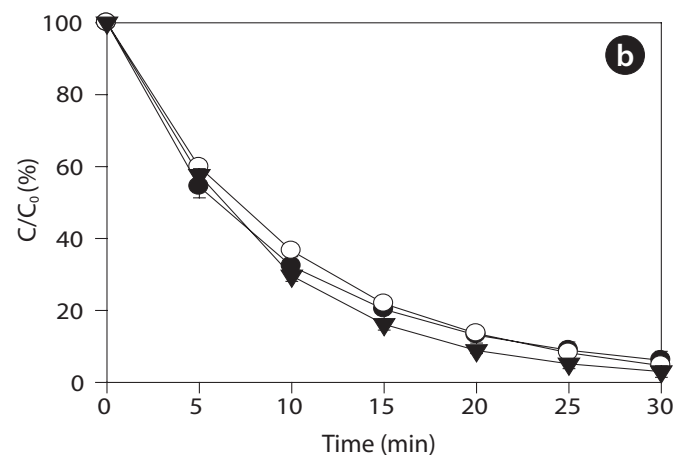

Fig. 10. Comparison of $17 \alpha$-ethinyl estradiol (EE2) sonodegradation in (a) synthetic brackish water (SBW) and (b) synthetic seawater (SSW) in the presence of dissolved organic carbon (DOC). (c) Comparison of pseudo-first order rate constants at different DOC concentrations. Sonication conditions: $0.2 \mathrm{~W} \mathrm{~mL}^{-1} ; 20 \pm$ $1{ }^{\circ} \mathrm{C} ; 580 \mathrm{kHz} ; \mathrm{pH} 7.5 ; \mathrm{C}_{0}=1 \mu \mathrm{M}(\bullet$ : no DOC (humic acid) added. $\circ: 3 \mathrm{mg} \mathrm{L}^{-1}$ DOC, $\left.\mathbf{\nabla}: 10 \mathrm{mg} \mathrm{L}^{-1} \mathrm{DOC}\right)$.

sonochemical processes is due to its recombination with $\mathrm{H} \bullet$ to reform water [63]. Such recombination reactions presumably occur because the two species are close to each other after their initial formation. This recombination process presents a major impediment to the efficient production of $\mathrm{HO} \cdot$. However, adding humic acids associated with background anions and cations 
trap $\mathrm{H} \bullet$, so they cannot recombine with $\mathrm{HO} \cdot$. The expected result of this trapping would be an increase in $\mathrm{HO} \cdot$ concentration in aqueous solution. However, a further detailed study is needed to clarify this matter. Measurements of DOC conducted during ultrasound irradiation in SBW and SSW showed different behaviors with respect to NOM removal. After $30 \mathrm{~min}$ of sonicating the humic acid solution, DOC removal varied depending on water type: $27 \%\left(3 \mathrm{mg} \mathrm{L}^{-1}\right)$ and $7 \%\left(10 \mathrm{mg} \mathrm{L}^{-1}\right)$ in SBW and 7\% (3 $\left.\mathrm{mg} \mathrm{L}^{-1}\right)$ and $4 \%\left(10 \mathrm{mg} \mathrm{L}^{-1}\right)$ in SSW. The effect of ultrasonic irradiation can be explained by two mechanisms: 1) chemical degradation of the humic acids occurs in the cavitation bubbles by oxidation; and 2) physical aggregation of humic acid fragments [31]. However, more extensive studies are needed to determine the transport and fate of NOM during sonodegradation, because the degradation of DOC (i.e., NOM) measured by $\mathrm{UVA}_{254}$ does not indicate that it was completely degraded or mineralized.

\section{Conclusions}

In this study, two endocrine disrupting compounds (i.e., BPA and EE2) were sonodegraded in DI water, SBW, and SSW at different frequencies. Ultrasound irradiation was efficient at degrading the EDCs, and the degradation varied depending on the background water chemistry. The degradation of EE2, which is relatively more hydrophobic than BPA, was slightly faster. Among these three types of water, the degradation of BPA and EE2 followed the order DI water $>$ SBW $>$ SSW at a contact time of $30 \mathrm{~min}$; this is because $\mathrm{HCO}_{3}^{-}$, a well-known $\mathrm{HO} \cdot$ scavenger, competes for available $\mathrm{HO} \bullet$ in the SBW and SSW solutions and decreases the BPA and EE2 reactions with $\mathrm{HO} \cdot$. Additionally, the results revealed that the degradation of EDCs is strongly influenced by sonication frequency, because a higher frequency of $580 \mathrm{kHz}$ typically increases the number of free radicals in the system. The degradation rate of BPA and EE2 at $580 \mathrm{kHz}$ increased slightly along with an increase in $\mathrm{pH}$ from 4 to 7.5 , whereas a significant increase in degradation was observed at $\mathrm{pH} 11$. For the given frequencies of 28 and $580 \mathrm{kHz}$, the degradation rate increased in the presence of glass beads for both BPA and EE2. The results also showed that a slight increase in degradation of both BPA and EE2 was found as the concentration of DOC increased in both SBW and SSW. A limited amount of NOM was removed during the sonodegradation of BPA and EE2.

\section{References}

1. Service RF. Desalination freshens up. Science 2006;313:10881090.

2. Sanza MA, Bonnélyea V, Cremerb G. Fujairah reverse osmosis plant: 2 years of operation. Desalination 2007;203:91-99.

3. Sauvet-Goichon B. Ashkelon desalination plant--a successful challenge. Desalination 2007;203:75-81.

4. Prihasto N, Liu QF, Kim SH. Pre-treatment strategies for seawater desalination by reverse osmosis system. Desalination 2009;249:308-316.

5. Al-Amoudi AS. Factors affecting natural organic matter (NOM) and scaling fouling in NF membranes: a review. Desalination 2010;259:1-10.

6. Cronan CS, Aiken GR. Chemistry and transport of soluble humic substances in forested watersheds of the Adirondack Park, New York. Geochim. Cosmochim. Acta 1985;49:1697-
1705.

7. Baronti C, Curini R, D’Ascenzo G, Di Corcia A, Gentili A, Samperi R. Monitoring natural and synthetic estrogens at activated sludge sewage treatment plants and in a receiving river water. Environ. Sci. Technol. 2000;34:5059-5066.

8. Snyder SA, Westerhoff P, Yoon Y, Sedlak DL. Pharmaceuticals, personal care products, and endocrine disruptors in water: implications for the water industry. Environ. Eng. Sci. 2003;20:449-469.

9. Yoon Y, Ryu J, Oh J, Choi BG, Snyder SA. Occurrence of endocrine disrupting compounds, pharmaceuticals, and personal care products in the Han River (Seoul, South Korea). Sci. Total Environ. 2010;408:636-643.

10. Heemken OP, Reincke H, Stachel B, Theobald N. The occurrence of xenoestrogens in the Elbe river and the North Sea. Chemosphere 2001;45:245-259.

11. Snyder S, Vanderford B, Pearson R, Quinones O, Yoon Y. Analytical methods used to measure endocrine disrupting compounds in water. Pract. Period. Hazard. Toxic Radioact. Waste Manage. 2003;7:224-234.

12. Adams C, Wang Y, Loftin K, Meyer M. Removal of antibiotics from surface and distilled water in conventional water treatment processes. J. Environ. Eng. 2002;128:253-260.

13. Trenholm RA, Vanderford BJ, Drewes JE, Snyder SA. Determination of household chemicals using gas chromatography and liquid chromatography with tandem mass spectrometry. J. Chromatogr. 2008;1190:253-262.

14. Vanderford BJ, Snyder SA. Analysis of pharmaceuticals in water by isotope dilution liquid chromatography/tandem mass spectrometry. Environ. Sci. Technol. 2006;40:73127320.

15. Alum A, Yoon Y, Westerhoff P, Abbaszadegan M. Oxidation of bisphenol A, 17 $\beta$-estradiol, and 17 $\alpha$-ethynyl estradiol and byproduct estrogenicity. Environ. Toxicol. 2004;19:257-264.

16. Zhang TC, Emary SC. Jar tests for evaluation of atrazine removal at drinking water treatment plants. Environ. Eng. Sci. 1999;16:417-432.

17. Yoon Y, Westerhoff P, Snyder SA, Esparza M. HPLC-fluorescence detection and adsorption of bisphenol $\mathrm{A}$, $17 \beta$-estradiol, and $17 \alpha$-ethynyl estradiol on powdered activated carbon. Water Res. 2003;37:3530-3537.

18. An D, Song JX, Gao W, Chen GG, Gao NY. Molecular weight distribution for nom in different drinking water treatment processes. Desalin. Water Treat. 2009;5:267-274.

19. De Gusseme B, Pycke B, Hennebel T, et al. Biological removal of $17 \alpha$-ethinylestradiol by a nitrifier enrichment culture in a membrane bioreactor. Water Res. 2009;43:2493-2503.

20. Snyder SA, Leising J, Westerhoff P, Yoon Y, Mash H, Vanderford B. Biological and physical attenuation of endocrine disruptors and pharmaceuticals: implications for water reuse. Ground Water Monit. Remediat. 2004;24:108-118.

21. Campinas M, Rosa MJ. Comparing PAC/UF and conventional clarification with PAC for removing microcystins from natural waters. Desalin. Water Treat. 2010;16:120-128.

22. Yoon Y, Amy G, Cho J, Her N. Effects of retained natural organic matter (NOM) on NOM rejection and membrane flux decline with nanofiltration and ultrafiltration. Desalination 2005;173:209-221.

23. Yu Z, Peldszus S, Huck PM. Adsorption characteristics of selected pharmaceuticals and an endocrine disrupting compound-Naproxen, carbamazepine and nonylphenol-on activated carbon. Water Res. 2008;42:2873-2882. 
24. Kimura K, Iwase T, Kita S, Watanabe Y. Influence of residual organic macromolecules produced in biological wastewater treatment processes on removal of pharmaceuticals by NF/ RO membranes. Water Res. 2009;43:3751-3758.

25. Yoon Y, Westerhoff P, Snyder SA. Adsorption of $3 \mathrm{H}$-labeled $17-\beta$ estradiol on powdered activated carbon. Water Air Soil Pollut. 2005;166:343-351.

26. Yoon Y, Westerhoff P, Snyder SA, Wert EC. Nanofiltration and ultrafiltration of endocrine disrupting compounds, pharmaceuticals and personal care products. J. Membr. Sci. 2006;270:88-100.

27. Suri RPS, Singh TS, Abburi S. Influence of alkalinity and salinity on the sonochemical degradation of estrogen hormones in aqueous solution. Environ. Sci. Technol. 2010;44:13731379.

28. Van Geluwea S, Braekena L, Vinckierb C, Van der Bruggen B. Ozonation and perozonation of humic acids in nanofiltration concentrates. Desalin. Water Treat. 2009;6:217-221.

29. Westerhoff P, Yoon Y, Snyder S, Wert E. Fate of endocrine-disruptor, pharmaceutical, and personal care product chemicals during simulated drinking water treatment processes. Environ. Sci. Technol. 2005;39:6649-6663.

30. Adewuyi YG. Sonochemistry: environmental science and engineering applications. Ind. Eng. Chem. Res. 2001;40:46814715.

31. Naddeo V, Belgiorno V, Napoli RMA. Behaviour of natural organic mater during ultrasonic irradiation. Desalination 2007;210:175-182.

32. De Bel E, Dewulf J, Witte BD, Van Langenhove H, Janssen C. Influence of $\mathrm{pH}$ on the sonolysis of ciprofloxacin: biodegradability, ecotoxicity and antibiotic activity of its degradation products. Chemosphere 2009;77:291-295.

33. Fu H, Suri RPS, Chimchirian RF, Helmig E, Constable R. Ultrasound-induced destruction of low levels of estrogen hormones in aqueous solutions. Environ. Sci. Technol. 2007;41:5869-5874.

34. Syracuse Research Corporation. Interactive PhysProp database demo [Internet]. Syracuse, NY: Syracuse Research Corporation; c2011 [cited 2011 Feb 4]. Available from: http:// www.syrres.com/what-we-do/databaseforms.aspx?id=386.

35. Al-Rasheed R, Cardin DJ. Photocatalytic degradation of humic acid in saline waters. Part 1. Artificial seawater: influence of $\mathrm{TiO}_{2}$, temperature, $\mathrm{pH}$, and air-flow. Chemosphere 2003;51:925-933.

36. Greenlee LF, Lawler DF, Freeman BD, Marrot B, Moulin P. Reverse osmosis desalination: water sources, technology, and today's challenges. Water Res. 2009;43:2317-2348.

37. AhrerW, Scherwenk E, Buchberger W. Determination of drug residues in water by the combination of liquid chromatography or capillary electrophoresis with electrospray mass spectrometry. J. Chromatogr. 2001;910:69-78.

38. Kormann C, Bahnemann DW, Hoffmann MR. Photocatalytic production of $\mathrm{H}_{2} \mathrm{O}_{2}$ and organic peroxides in aqueous suspensions of $\mathrm{TiO}_{2}, \mathrm{ZnO}$, and desert sand. Environ. Sci. Technol. 1988;22:798-806.

39. Suslick KS, Schubert PF, Goodale JW. Sonochemistry and sonocatalysis of iron carbonyls. J. Am. Chem. Soc. 1981;103:7342-7344.

40. Pétrier C, Lamy MF, Francony A, et al. Sonochemical degradation of phenol in dilute aqueous solutions: comparison of the reaction rates at 20 and $487 \mathrm{kHz}$. J. Phys. Chem. 1994;98:10514-10520.
41. Gogate PR. Treatment of wastewater streams containing phenolic compounds using hybrid techniques based on cavitation: a review of the current status and the way forward. Ultrason. Sonochem. 2008;15:1-15.

42. Kidak R, Ince NH. Ultrasonic destruction of phenol and substituted phenols: a review of current research. Ultrason. Sonochem. 2006;13:195-199.

43. Kotronarou A, Mills G, Hoffmann MR. Ultrasonic irradiation of p-nitrophenol in aqueous solution. J. Phys. Chem. 1991;95:3630-3638.

44. Ma J, Graham NJD. Degradation of atrazine by manganesecatalysed ozonation--influence of radical scavengers. Water Res. 2000;34:3822-3828.

45. Cheng J, Vecitis CD, Park H, Mader BT, Hoffmann MR. Sonochemical degradation of perfluorooctane sulfonate (PFOS) and perfluorooctanoate (PFOA) in landfill groundwater: environmental matrix effects. Environ. Sci. Technol. 2008;42:8057-8063.

46. Torres RA, Pétrier C, Combet E, Carrier M, Pulgarin C. Ultrasonic cavitation applied to the treatment of bisphenol A. Effect of sonochemical parameters and analysis of BPA byproducts. Ultrason. Sonochem. 2008;15:605-611.

47. Torres RA, Pétrier C, Combet E, Moulet F, Pulgarin C. Bisphenol A mineralization by integrated ultrasound-UV-iron (II) treatment. Environ. Sci. Technol. 2007;41:297-302.

48. Huber MM, Canonica S, Park GY, von Gunten U. Oxidation of pharmaceuticals during ozonation and advanced oxidation processes. Environ. Sci. Technol. 2003;37:1016-1024.

49. Behnajady MA, Modirshahla N, Tabrizi SB, Molanee S. Ultrasonic degradation of Rhodamine $\mathrm{B}$ in aqueous solution: influence of operational parameters. J. Hazard. Mater. 2008;152:381-386.

50. Ince NH, Tezcanli G, Belen RK, Apikyan IG. Ultrasound as a catalyzer of aqueous reaction systems: the state of the art and environmental applications. Appl. Catal. B Environ. 2001;29:167-176.

51. Furman O, Laine DF, Blumenfeld A, et al. Enhanced reactivity of superoxide in water--solid matrices. Environ. Sci. Technol. 2009;43:1528-1533.

52. Asakura Y, Nishida T, Matsuoka T, Koda S. Effects of ultrasonic frequency and liquid height on sonochemical efficiency of large-scale sonochemical reactors. Ultrason. Sonochem. 2008;15:244-250.

53. Shimizu N, Ogino C, Dadjour MF, Murata T. Sonocatalytic degradation of methylene blue with $\mathrm{TiO}_{2}$ pellets in water. $U l$ trason. Sonochem. 2007;14:184-190.

54. Wang J, Pan Z, Zhang Z, et al. Sonocatalytic degradation of methyl parathion in the presence of nanometer and ordinary anatase titanium dioxide catalysts and comparison of their sonocatalytic abilities. Ultrason. Sonochem. 2006;13:493-500.

55. Segebarth N, Eulaerts O, Reisse J, Crum LA, Matula TJ. Correlation between acoustic cavitation noise, bubble population, and sonochemistry. J. Phys. Chem. B 2002;106:9181-9190.

56. Crum LA. Comments on the evolving field of sonochemistry by a cavitation physicist. Ultrason. Sonochem. 1995;2:S147S152.

57. Burdin F, Tsochatzidis NA, Guiraud P, Wilhelm AM, Delmas H. Characterisation of the acoustic cavitation cloud by two laser techniques. Ultrason. Sonochem. 1999;6:43-51.

58. Lee J, Ashokkumar M, Kentish S, Grieser F. Determination of the size distribution of sonoluminescence bubbles in 
a pulsed acoustic field. J. Am. Chem. Soc. 2005;127:1681016811.

59. Tsochatzidis NA, Guiraud P, Wilhelm AM, Delmas H. Determination of velocity, size and concentration of ultrasonic cavitation bubbles by the phase-Doppler technique. Chem. Eng. Sci. 2001;56:1831-1840.

60. Bai Lx, Xu Wl, Tian Z, Li Nw. A high-speed photographic study of ultrasonic cavitation near rigid boundary. J. Hydrodyn. 2008;20:637-644.

61. Kanthale P, Ashokkumar M, Grieser F. Sonoluminescence, sonochemistry $\left(\mathrm{H}_{2} \mathrm{O}_{2}\right.$ yield) and bubble dynamics: frequency and power effects. Ultrason. Sonochem. 2008;15:143-150.

62. Taylor E Jr., Cook BB, Tarr MA. Dissolved organic matter in- hibition of sonochemical degradation of aqueous polycyclic aromatic hydrocarbons. Ultrason. Sonochem. 1999;6:175183.

63. Joseph JM, Destaillats H, Hung HM, Hoffmann MR. The sonochemical degradation of azobenzene and related azo dyes: rate enhancements via Fenton's reactions. J. Phys. Chem. A 2000;104:301-307.

64. Kosky PG, Silva J M, Guggenheim EA. The aqueous phase in the interfacial synthesis of polycarbonates. 1. Ionic equilibria and experimental solubilities in the BPA-NaOH- $\mathrm{H}_{2} \mathrm{O}$ system. Industrial \& Engineering Chemistry Research 1991;30: 462-467. 